\title{
LA CARTA DE DERECHOS FUNDAMENTALES DE LA UE Y LA JURISPRUDENCIA DEL TRIBUNAL EUROPEO DE DERECHOS HUMANOS'
}

\author{
LUIS LÓPEZ GUERRA² \\ Universidad Carlos III de Madrid \\ lopez@der-pu.uc3m.es
}

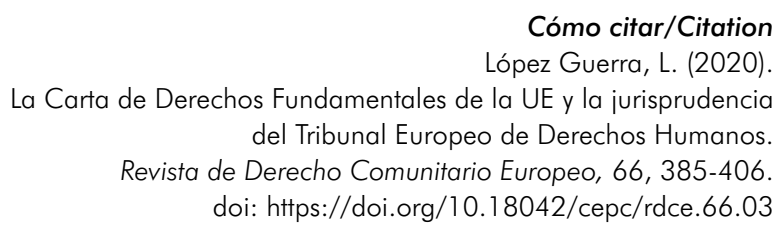

Resumen

La aprobación en 2000 de la Carta de Derechos Fundamentales y su entrada en vigor efectiva en 2009 han dado lugar a un fenómeno de indudable interés, al afectar al sentido de las relaciones entre el sistema de protección de derechos humanos establecido por el Convenio Europeo de Derechos Humanos y el sistema de integración supranacional representado por la Unión Europea. En efecto, y durante un considerable lapso de tiempo, la dirección de los influjos de un sistema sobre el otro, en materia de derechos humanos, parecía claramente ir del sistema del Convenio Europeo hacia la Comunidad, luego Unión Europea; sin embargo, a partir de la aprobación de la Carta, este flujo unidireccional ha ido transformándose cada vez más en una relación integrada por influencias recíprocas.

1 El presente texto recoge la intervención del autor, con el mismo título, el 17 de febrero de 2020, en el Seminario Gil Carlos Rodríguez Iglesias sobre «Diez años de aplicación de la Carta de Derechos Fundamentales de la Unión Europea». Se han añadido algunas notas.

2 Catedrático de Derecho Constitucional. Exjuez del Tribunal Europeo de Derechos Humanos (2008-2018). 


\title{
Palabras clave
}

Convenio Europeo de Derechos Humanos; Tribunal Europeo de Derechos Humanos; Carta de Derechos Fundamentales; Tribunal de Justicia de la Unión Europea.

\section{THE CHARTER OF FUNDAMENTAL RIGHTS OF THE EU AND THE CASE LAW OF THE EUROPEAN COURT OF HUMAN RIGHTS}

\begin{abstract}
The approval and subsequent entry into force of the Charter of Fundamental Rights of the European Union has given rise to an interesting phenomenon, affecting the relationship between the system of protection of human rights set forth in the European Convention on Human Rights and the European Union's system of European integration. For many years, the European Convention system provided the European Union's main source of inspiration in matter of human rights. However, after the Charter's entry into force, that unidirectional influence has evolved towards a system of reciprocal influences.
\end{abstract}

\section{Keywords}

European Convention on Human Rights; European Court of Human Rights; Charter of Fundamental Rights; Court of Justice of the European Union.

\section{LA CHARTE DES DROITS FONDAMENTAUX DE L'UE ET LA JURISPRUDENCE DE LA COUR EUROPÉENNE DES DROITS DE L'HOMME}

\section{Resumé}

L'approbation en 2000 de la Charte des droits fondamentaux et son entrée en vigueur effective en 2009 ont donné lieu à un phénomène d'intérêt incontestable, en affectant le sens des relations entre le système de protection des droits de l'homme établi par la Convention européenne des droits de l'homme et le système d'intégration supranational représenté par l'Union européenne. En effet, et pendant une période de temps considérable, la direction des influences d'un système sur l'autre, en termes de droits de l'homme, semblait clairement aller du système de la Convention européenne vers la Communauté, puis l'Union européenne; cependant, depuis l'approbation de la Charte, ce flux à sens unique s'est de plus en plus transformé en une relation faite d'influences réciproques.

\section{Mots clés}

Convention européenne des droits de l'homme; Cour européenne des droits de l'homme; Charte des droits fondamentaux; Cour de justice de l'Union européenne. 


\section{SUMARIO}

I. EL PUNTO DE PARTIDA: LA REMISIÓN DEL ORDENAMIENTO COMUNITARIO AL CONVENIO. II. LA CARTA DE DERECHOS Y SU PROYECCIÓN EN EL SISTEMA DEL CONVENIO. III. CARTA DE DERECHOS Y CAMBIOS EN LA JURISPRUDENCIA DEL TEDH. IV. LA ENTRADA EN VIGOR DE LA CARTA, LA JURISPRUDENCIA DEL TJUE Y SU PROYECCIÓN SOBRE EL TEDH. V. LA CARTA DE DERECHOS Y EL DIÁLOGO ENTRE ESTRASBURGO Y LUXEMBURGO: LOS CASOS SOBRE EL NE BIS IN IDEM. BIBLIOGRAFÍA.

La aprobación en 2000 de la Carta de Derechos Fundamentales y su entrada en vigor efectiva en 2009 han dado lugar a un fenómeno de indudable interés, al afectar al sentido de las relaciones entre el sistema de protección de derechos humanos establecido por el Convenio Europeo de Derechos Humanos y el sistema de integración supranacional representado por la Unión Europea. En efecto, y durante un considerable lapso de tiempo, la dirección de los influjos de un sistema sobre el otro, en materia de derechos humanos, parecía claramente ir del sistema del Convenio Europeo hacia la Comunidad, luego Unión Europea; sin embargo, a partir de la aprobación de la Carta, este flujo unidireccional ha ido transformándose cada vez más en una relación integrada por influencias recíprocas.

\section{EL PUNTO DE PARTIDA: LA REMISIÓN DEL ORDENAMIENTO COMUNITARIO AL CONVENIO}

Por lo que se refiere a la primera fase, hasta la entrada en vigor de la Carta, es bien conocida la evolución dentro de la Unión (antes Comunidad) Europea del reconocimiento del papel dentro de su ordenamiento de los derechos fundamentales, a pesar de la inicial falta de mención a los mismos en los textos fundacionales. Primeramente a través de la denominada labor pretoriana del Tribunal de Justicia (iniciada en sus muy citadas sentencias Stauder e Internationale Handelsgesseschaft entre otras ${ }^{3}$ ) y posteriormente a través de un

3 Sentencias del Tribunal de Justicia de 12 de noviembre de 1969, Stauder, 29/69, EU:C:1969:57 y de 17 de diciembre de 1970, Internationale Handelsgesellschaft, 11-70, EU:C:1970:114 
reconocimiento por remisión en el derecho básico de la Unión (Preámbulo al Acta Única Europea de 19864, Tratado de Maastricht en 19925) la Unión lleva a cabo una incorporación de los derechos fundamentales a su ordenamiento por medio de expresas referencias a tres fuentes de derechos: el Convenio Europeo de Derechos Humanos, los principios generales del derecho europeo y las tradiciones constitucionales comunes de los países miembros ${ }^{6}$. Por su propia naturaleza y mayor precisión, las normas del Convenio y su interpretación por el Tribunal Europeo de Derechos Humanos representaban el núcleo esencial orientador en la aplicación de los derechos de la persona en la actuación de los poderes comunitarios, como pudo reflejarse, por ejemplo, en la jurisprudencia del Tribunal de Luxemburgo.

La adopción del sistema del Convenio como punto de referencia privilegiado a la hora de determinar el régimen de los derechos fundamentales en el ordenamiento comunitario se reflejó incluso en el mismo texto de la Carta adoptada en 2000. En su Preámbulo la Carta reafirma el papel al respecto, no solo del Convenio Europeo de Derechos Humanos, sino también de la jurisprudencia del Tribunal de Estrasburgo; lo que se concreta en su art. 52.1.3, que establece que «En la medida en que la presente Carta contenga derechos que correspondan a derechos garantizados por el Convenio Europeo para la Protección de los Derechos Humanos y de las Libertades Fundamentales, su sentido y alcance serán iguales a los que les confiere dicho Convenio». Y finalmente, y hasta el momento, la remisión al sistema del Convenio se consagra expresamente en el art. 6.3 del Tratado de la Unión 7 .

La entrada en vigor de la Carta con carácter vinculante a partir de 2009 no ha supuesto una alteración de esta situación, no solo por la previsión del

4 En que se proclama la decisión de los países miembros de «promover conjuntamente la democracia, basándose en los derechos fundamentales reconocidos en las Constituciones y leyes de los Estados miembros, en el Convenio Europeo para la Protección de los Derechos Humanos y de las Libertades Fundamentales y en la Carta Social Europea, en particular la libertad, la igualdad y la justicia social».

5 El apartado segundo del art. 6 proclama que «la UE respetará los derechos fundamentales tal y como se garantizan en el Convenio Europeo para la protección de los Derechos Humanos y de las Libertades Fundamentales firmado en Roma el 4 de noviembre de 1950 y tal y como resultan de las tradiciones constitucionales comunes a los Estados miembros como principios generales del Derecho Comunitario».

6 Para un comentario a este respecto, véase Rubio Llorente (2002: 169-201).

7 «Los derechos fundamentales que garantiza el Convenio Europeo para la Protección de los Derechos Humanos y de las Libertades Fundamentales y los que son fruto de las tradiciones constitucionales comunes a los Estados miembros formarán parte del Derecho de la Unión como principios generales». 
citado artículo, sino también, en la práctica, por la atención del Tribunal de Justicia a los mandatos del Convenio y a la jurisprudencia de Estrasburgo. Ciertamente, el Tribunal de Justicia utiliza preferentemente la Carta como punto de referencia en la determinación de los derechos fundamentales en el sistema de la Unión, y construye en su jurisprudencia sus propios conceptos autónomos; pero siguen siendo relevantes en esa jurisprudencia, tanto los mandatos del Convenio como la jurisprudencia de Estrasburgo, considerada por el Tribunal de Justicia, a la luz del art. 52.1.3 de la Carta, si no como la ratio decidendi de sus resoluciones, sí como fuente de conocimiento jurídico, de considerable importancia (Engel, 2015: 35; Rauchegger y Lambrecht, 2016: 45-55).

La jurisprudencia del Tribunal de Justicia, en efecto, ha reconocido consistentemente el papel del Convenio y de la jurisprudencia del Tribunal de Estrasburgo. Baste señalar dos ejemplos, desde el momento de la entrada en vigor de la Carta hasta el momento actual. Ya en los inicios de esa fase de entrada en vigor, el Tribunal de Justicia, en J. McB. v L.E, de 2010, insistió en que "Asimismo, del artículo 52, apartado 3, de la Carta resulta que, en la medida en que esta contenga derechos que correspondan a derechos garantizados por el $\mathrm{CEDH}$, su sentido y alcance serán iguales a los que les confiere este» ${ }^{8}$, y fundamentó expresamente su decisión, para interpretar el art. 7 de la Carta en un caso relativo a la potestad materna de trasladar a un menor al extranjero, en la doctrina del Tribunal de Estrasburgo en Zaunegger contra Alemania, sentencia que interpretaba el art. 8 del Convenio sobre derechos correspondientes a los reconocidos en el citado art. 7 de la Carta ${ }^{9}$. Y, para citar otro ejemplo casi diez años después, el Tribunal de Luxemburgo mantuvo esa posición de deferencia hacia el Convenio y su interpretación por el Tribunal de Estrasburgo en Abubacar Jawo contra la República Federal de Alemania ${ }^{10}$, en que, para fundamentar su decisión sobre la legitimidad de una orden de traslado de una persona a otros país, caso de riesgo para su integridad por deficiencias bien sistémicas o generalizadas, o bien que afectaran a ciertos grupos de personas, aplicando el art. 4 de la Carta, vino a referirse como argumento para su decisión a la interpretación del correspondiente art. 3 del

8 Sentencia del Tribunal de Justicia de 5 de octubre de 2010, J. McB, C-400/10 PPU, EU:C:2010:582, apdo. 53.

9 Sentencia del TEDH de 3 de diciembre de 2009, Zaunegger c. Alemania, CE: ECHR:2009:1203JUD002202804.

10 Sentencia del Tribunal de Justicia de 19 de marzo de 2019, Abubacarr Jawo C-163/17, EU:C:2019:218. 
Convenio por el Tribunal de Estrasburgo en su sentencia MSS contra Bélgica y Grecia, de $2011^{11}$.

\section{LA CARTA DE DERECHOS Y SU PROYECCIÓN EN EL SISTEMA DEL CONVENIO}

La aprobación de la Carta Europea y su posterior entrada en vigor con fuerza vinculante supusieron la aparición de un nuevo punto de referencia en el contexto regional europeo en lo que se refiere a la protección de los derechos fundamentales. La Carta venía a expresar el surgimiento de un sistema comunitario autónomo de protección de esos derechos, paralelo al sistema del Convenio e independiente del mismo; sistema derivado primeramente de la misma existencia de la Carta como manifestación de unos valores compartidos por los Estados de la Unión, y más adelante de la efectiva aplicación de su contenido por la jurisprudencia del Tribunal de Luxemburgo. Y, como podía preverse desde el primer momento, y como la práctica ha confirmado, en la misma forma que el sistema del Convenio se había proyectado en el régimen de derechos fundamentales de la Unión, como se ha indicado, la aparición de la Carta y su aplicación jurisprudencial ha implicado que ahora sea el sistema de la Unión el que se proyecte en el sistema del Convenio, y específicamente en la jurisprudencia del Tribunal de Estrasburgo.

Así y todo, conviene tener en cuenta que esa proyección se ha producido aun cuando en el sistema del Convenio (a diferencia del sistema de la Unión, en el que se integran expresamente mandatos en sus textos primarios que se refieren expresamente al Convenio y a la jurisprudencia del Tribunal Europeo de Derechos Humanos) únicamente el mismo Convenio y sus Protocolos se configuran como fuente formalmente establecida para la protección de los derechos fundamentales por los órganos del sistema ${ }^{12}$. Valga recordar además que si bien todos los miembros del sistema comunitario, desde su principio, estaban también integrados en el sistema del Convenio ${ }^{13}$, una buena parte de los 47 Estados firmantes del Convenio no son miembros de la Unión Europea.

11 Sentencia del TEDH de 21 de enero de 2011, M.S.S. c. Bélgica y Grecia, CE: ECHR:2011:0121JUD003069609.

12 La única referencia a la Unión Europea es la contenida en el art. 59.2 del Convenio, introducido por la reforma llevada a cabo por el Protocolo 14, en 2010: «La Unión Europea podrá adherirse al Convenio».

13 Francia firmó el Convenio en 1950, aunque no lo ratificó hasta 1974. 
La toma en cuenta por parte del Tribunal de Estrasburgo de los preceptos de la Carta no se ha llevado a cabo, pues, en virtud de mandato específico alguno, sino a través de la aplicación de criterios de orden general en la jurisprudencia del Tribunal, aplicables también a otros instrumentos internacionales de protección de derechos, incluso de alcance territorial distinto al del Convenio: tal sería el caso, por ejemplo, dentro del mismo ámbito territorial europeo, de la Carta Social Europea, o en ámbitos distintos, de la Convención Americana de Derechos Humanos. Y ello lo ha llevado a cabo, por otra parte, dentro de los moldes usuales del derecho internacional; ha podido señalarse así que el Tribunal se remite con generalidad a los mandatos de interpretación contenidos en la Convención de Viena sobre la Interpretación de los Tratados, y que el art. 31.3 de esa Convención establece que para la interpretación del texto de un tratado, «juntamente con el contexto habrá de tenerse en cuenta: c) toda forma pertinente de Derecho internacional aplicable en las relaciones entre las partes» (Dickson, 2015: 28). Ciertamente, la Unión Europea no es aún parte del Convenio, pero a la vista de la pertenencia a la Unión de 27 (antes del Brexit, 28) de los Estados firmantes del Convenio, el Tribunal no ha tenido dificultad en aplicar en la práctica esa disposición, incluso sin necesidad de referencia expresa.

El Tribunal de Estrasburgo tuvo oportunidad de expresar su opinión sobre el papel de los instrumentos de derecho internacional de los derechos humanos en la interpretación del Convenio en su sentencia en el caso Demir y Baykara contra Turquía, en el año 2008, en relación con el derecho de sindicación de los funcionarios, y su inclusión en el ámbito del art. 11 del Convenio. En palabras de la sentencia: «El Tribunal, para definir el sentido de los términos y conceptos del Convenio, puede y debe tener en cuenta otros elementos del Derecho internacional aparte del Convenio, la interpretación de esos elementos por los órganos competentes y la práctica de los Estados europeos que refleja sus valores comunes. El consenso resultante de instrumentos internacionales especializados y de la práctica de los Estados parte puede constituir una consideración relevante para el Tribunal cuando interpreta los mandatos del Convenio en casos específicos» ${ }^{14}$.

En el caso concreto, y para llegar a una conclusión de violación por Turquía del derecho reconocido en el art. 11 del Convenio, el Tribunal se refiere, entre otros, al Pacto Internacional de Derechos Económicos Sociales y Culturales, al Pacto sobre Derechos Civiles y Políticos, al Convenio núm. 87 de la OIT sobre libertad de asociación y protección del derecho a sindicarse,

14 Sentencia del TEDH de 12 de noviembre de 2008, Demir y Baykara c. Turquía, CE: ECHR:2008:1112JUD003450397, párr. 85. 
a la Carta Social Europea y, de interés en estas líneas, al art. 12.1 de la Carta de Derechos Fundamentales, que declara que «todos tienen derecho a formar y a unirse a sindicatos para la protección de sus intereses", así como a su art. 28 , referente al derecho a acordar convenios colectivos. Y, en relación con un punto señalado más arriba, esto es, que hay Estados firmantes del Convenio que no son parte de la Unión Europea, y que por ello no estarían vinculados por una interpretación del Convenio derivada de los instrumentos constitutivos de esta, el Tribunal hace una reflexión al respecto:

En este contexto no es necesario que el Estado demandado haya ratificado toda la serie de instrumentos internacionales que sean aplicables respecto de la precisa cuestión objeto del caso de que se trate. Será suficiente para el Tribunal que los instrumentos internacionales relevantes muestren una continua evolución de las normas y principios aplicados en Derecho internacional o en el Derecho interno de la mayoría de los Estados del Consejo de Europa, así como, en un área determinada, que existe una base común en las sociedades modernas (párr. 86).

La concreta inclusión o no inclusión de un Estado en el ámbito de un tratado internacional sobre derechos humanos no resulta pues elemento indispensable para que el Tribunal tenga en cuenta ese instrumento para la interpretación del Convenio al tratar algún caso respecto de la eventual vulneración por ese Estado de un derecho del Convenio, si las disposiciones de ese tratado reflejan una evolución en los ordenamientos de la mayoría de los Estados europeos o si representan un elemento generalmente reconocido en los diversos ámbitos nacionales. En el caso, ello llevó a la condena de Turquía sobre la base de la interpretación del art. 11 del Convenio a la luz de instrumentos internacionales no ratificados por ese país. Y, por lo que se refiere a la práctica del Tribunal, en cuanto a "tener en cuenta» el derecho de la Unión Europea, y en particular la Carta de Derechos Fundamentales, el Tribunal no ha vacilado en llevar a cabo una interpretación del Convenio a la vista de las disposiciones de aquella, respecto de demandas contra países no incluidos en la Unión Europea (así, aparte de Demir y Baykara, en Bayatyan contra Armenia, de 2011, o Roman Zakharov contra Rusia, de 2015, entre otros muchos) ${ }^{15}$.

Desde esta perspectiva, el Tribunal de Estrasburgo no ha tenido dificultad en hacer continuas referencias a la Carta, desde su misma aprobación y antes de que adquiriera carácter vinculante. Y ello en las más variadas materias; tanto en lo que respecta a la interpretación de derechos sustantivos reconocidos en el

15 Sentencia del TEDH de 7 de julio de 2011, Bayatyan c. Armenia, CE:ECHR:2011:0707JUD002345903y de4dediciembrece2015, Roman Zakharovc. Rusia, CE:ECHR: 2015:1204JUD004714306. 
Convenio (así en cuanto al derecho a la vida privada del art. 8 o al derecho a contraer matrimonio del art. 12) como en lo que respecta a derechos de índole procesal en la garantía de un juicio equitativo. Valga decir que esta referencia al texto de la Carta se ha hecho en formas diversas y con variada intensidad. En determinadas sentencias se cita la Carta en la parte del texto relativa a las normas nacionales e internacionales de relevancia para el caso; en otras, las citas se producen al reproducir las alegaciones de las partes; en numerosas sentencias, yendo más allá, la referencia a la Carta se lleva a cabo al exponer los razonamientos jurídicos contenidos en la argumentación del Tribunal. Pero donde se muestra con una mayor intensidad la atención a los mandatos de la Carta es en aquellos supuestos en que esos mandatos dan lugar a cambios de la jurisprudencia del Tribunal de Estrasburgo; si no como ratio decidendi para ese cambio, sí como muy significativos obiter dicta.

\section{CARTA DE DERECHOS Y CAMBIOS EN LA JURISPRUDENCIA DEL TEDH}

Son ciertamente estos casos los que muestran más claramente la aparición de un flujo de reconocimientos e influencias recíprocas entre los dos sistemas. Quizás uno de los ejemplos más llamativos sea el que representa la sentencia Christine Goodwin contra Reino Unido, del año 2002, en una cuestión relativa a los derechos de las personas transexuales, poco después de la aprobación de la Carta y cuando aún no se le reconocía fuerza vinculante ${ }^{16}$. El tema que se planteaba era el del reconocimiento del estatus legal de una persona que había sido objeto de una intervención para cambio de sexo (de masculino a femenino) por el Servicio Nacional de la Salud del Reino Unido, de carácter estatal. A pesar de esa intervención, no se había trasladado ese hecho oficialmente al Registro Civil, ni a los certificados de nacimiento, con lo que la persona afectada mantenía su anterior estatus legal masculino. Como consecuencia, y entre otros problemas, no se le reconocía la posibilidad de contraer matrimonio con una persona de su sexo inicial, masculino, lo que, aducía, vulneraba su derecho al matrimonio del art. 12 del Convenio.

El Tribunal, en su jurisprudencia anterior ${ }^{17}$, se había atenido a la literalidad del art. 12 («el hombre y la mujer tienen derecho a casarse y a fundar una

16 Sentencia del TEDH de 11 de julio de 2002, Goodwin c. Reino Unido, CE: ECHR:2002:0711JUD002895795.

17 Sentencias del TEDH de 14 de octubre de 1986, Rees c. Reino Unido, CE: ECHR:1986:1017JUD000953281, de 27 de septiembre de 1990, Cossey c. Rei- 
familia según las leyes nacionales») y por lo tanto consideraba que los Estados tenían un amplío margen de apreciación para establecer las condiciones de matrimonio en lo que se refería a las personas transexuales; en consecuencia, la prohibición de matrimonio con una persona del sexo inicial del transexual no se oponía al art. 12. Pero en Goodwin el Tribunal cambió expresamente de criterio. En sus propias palabras,

ha habido profundos cambios sociales en la institución del matrimonio, así como cambios dramáticos derivados del desarrollo de la medicina y la ciencia en el campo de la transexualidad. [...] el examen de los factores biológicos no puede ya ser decisivo para denegar un reconocimiento legal al cambio de género de un transexual tras su operación [...]. El Tribunal toma nota también de que el artículo 9 de la Carta de Derechos Fundamentales de la Unión Europea recientemente adoptada se separa, deliberadamente sin duda, de la literalidad del artículo 12 del Convenio, al eliminar la referencia a hombre y mujer ${ }^{18}$.

El Tribunal concluye que la prohibición de matrimonio de una persona transexual con otra de su sexo originario representa una violación del art. 12 del Convenio.

Adicionalmente, la línea sentada en Goodwin ha servido para que el Tribunal mantenga, en casos posteriores, la utilización del art. 9 de la Carta para interpretar los mandatos del art. 12 del Convenio, en materias como el ámbito del margen de apreciación de los Estados respecto al matrimonio entre personas del mismo sexo, así como en lo referente al régimen de las uniones no matrimoniales. En cuanto a lo primero, el Tribunal, en Schalk y Kopf contra Austria, de 2010, indicó que teniendo en cuenta el art. 9 de la Carta, el Tribunal no podía considerar ya que el derecho a contraer matrimonio consagrado en el art. 12 debiera limitarse en todas las circunstancias a dos personas de sexo contrario; a la vista de la diferencia de posiciones al respecto en los diversos Estados del Convenio, el Tribunal prefiere dejar la cuestión de la autorización o no del matrimonio entre personas del mismo sexo a la regulación de las leyes de cada Estado ${ }^{19}$. Por lo que atañe a las uniones no matrimoniales, el Tribunal, en Vallianatos contra Grecia, de 2013, a la luz del art. 9 de la Carta, consideró contraria a la prohibición de discriminación

no Unido, CE:ECHR:1990:0927JUD001084384 1990 y de 30 de julio de 1998, Sheffield y Horsam c. Reino Unido, CE:ECHR:1998:0730JUD002298593.

18 Sentencia Goodwin, citada nota 16, párr. 100.

19 Sentencia del TEDH de 24 de junio de 2010, Schalk y Kopf c. Austria, CE: ECHR:2010:0624JUD003014104, $\$ 52$. 
del art. 14 en relación con el art. 8 del Convenio la limitación de esas uniones a parejas de distinto sexo ${ }^{20}$.

Ejemplo también de una utilización de la Carta, antes de que cobrara fuerza vinculante, es la Sentencia Vilho Eskelinen contra Finlandia, de 2007, en que el Tribunal altera la línea jurisprudencial establecida en sentencias anteriores $^{21}$ y que, salvo excepciones de tipo funcional, venía a excluir del derecho a un proceso equitativo del art. 6 del Convenio a las demandas referentes a los litigios relativos a la función pública, por considerar que no se referían a «derechos y obligaciones de orden civil». El Tribunal utiliza los mandatos del art. 47 de la Carta, que versa sobre ese derecho a un proceso equitativo, para alterar su doctrina anterior. Primeramente, en la sección relativa al derecho europeo relevante, el Tribunal, en su sentencia, reconoce que

en el Derecho de la Unión, el derecho a un tribunal no se aplica únicamente a litigios relativos a derechos y obligaciones de carácter civil [...] Sin embargo, con la excepción de su ámbito de aplicación, las garantías ofrecidas por el Convenio Europeo de Derechos Humanos se aplican de una manera similar en la Unión. De ello se desprende que el artículo 47 de la Carta, en virtud de la legislación de la Unión Europea, no se limita a los derechos y obligaciones de los casos civiles y penales en el sentido del artículo 6 del Convenio ${ }^{22}$.

$\mathrm{Y}$ en sus fundamentos jurídicos, tras hacer referencia a la sentencia del Tribunal de Justicia en el caso Marguerite Johnston contra Jefe de Policía de la Real Policía del Ulster, señala que: «Este precedente y otros, en temas relacionados con el Derecho comunitario, muestran que en el Derecho de la Unión Europea, el alcance de la aplicabilidad del control judicial es enorme. Cuando una persona tiene un derecho sustantivo garantizado por el Derecho comunitario, su condición de titular del poder público no hace inaplicables los requisitos del control judicial (párr. 60)».

Partiendo de esta perspectiva, el Tribunal, en su jurisprudencia a partir de Vilho Eskelinen (por ejemplo, en Regner contra República Checa, de 201723) ha

20 Sentencia del TEDH de 7 de noviembre de 2013, Vallianatos y otros c. Grecia, CE: ECHR:2013:1107JUD002938109.

21 Así, la sentencia del TEDH de 8 de diciembre de 1999, Pellegrin c. Francia, CE: ECHR:1999:1208JUD002854195.

22 Sentencia del TEDH de 19 de abril de 2007, Vilho Eskelinen o otros c. Finlandia, CE: ECHR:2007:0419JUD006323500, \$30.

23 Sentencia del TEDH de 19 de septiembre de 2017, Regner c. República Checa, CE: ECHR:2017:0919JUD003528911. 
considerado, frente a su doctrina anterior, que en general los litigios referentes a la relación funcionarial están protegidos por el art. 6.1; si bien ha admitido alguna excepción, en lo que se refiere a posiciones que pudieran considerarse como cargos políticos, no se justifica la exclusión de las garantías del art. 6.1 en los conflictos de la función pública relativos a condiciones ordinarias del trabajo, como los sueldos, las indemnizaciones o cuestiones similares.

No menos relevante, por citar otro ejemplo, es la atención que el Tribunal de Estrasburgo presta a la Carta, también antes de su entrada en vigor, en la sentencia en el caso Scoppola contra Italia (2), de 2009 ${ }^{24}$. En esta sentencia, de nuevo el Tribunal altera la doctrina heredada de la Comisión Europea de Derechos Humanos, a la vista de las previsiones de la Carta. La Comisión (X contra Alemania, 1978 ${ }^{25}$ ) no había considerado que la prohibición de la retroactividad de las penas del art. 7 del Convenio resultara también en un mandato de retroactividad de la ley penal menos gravosa. Pero en Scoppola 2, el Tribunal, tras citar en la parte documental el art. 49 de la Carta, señala expresamente en la motivación de su fallo que la literalidad del art. 49 se aparta (sin duda deliberadamente, dice el Tribunal) del texto del art. 7 del Convenio en cuanto que precisa que si, posteriormente a la infracción en cuestión, la ley prevé una pena más ligera, esta es la que debe aplicarse; y el Tribunal deduce que «se ha ido formando progresivamente un consenso a nivel europeo e internacional para considerar que la aplicación de la ley penal que prevé una pena menos gravosa, incluso posterior a la comisión de la infracción, se ha convertido en un principio fundamental del Derecho penal ${ }^{26}$.

\section{LA ENTRADA EN VIGOR DE LA CARTA, LA JURISPRUDENCIA DEL TJUE Y SU PROYECCIÓN SOBRE EL TEDH}

Como era de esperar, las referencias a la Carta en supuestos de cambios de jurisprudencia del Tribunal se vieron reforzadas por la asunción por la Carta de fuerza vinculante, a partir de la entrada en vigor del Tratado de la Unión Europea, en 2009. Así, en Micallef contra Malta, de 2010, el Tribunal rectificó su posición anterior en el sentido de no aplicar las garantías procesales

24 Sentencia del TEDH de 17 de septiembre de 2009, Scoppola c. Italia ( $\left.n^{o} 2\right)$, CE: ECHR:2009:0917JUD001024903

25 Decisión de la Comisión Europea de Derechos Humanos de 6 de marzo de 1978, Xc. Alemania, CE:ECHR:1978:0306DEC000790077.

26 Sentencia Scoppola c. Italia ( $\left.n^{\circ} 2\right)$, citada en nota 24, párr. 106. 
del art. 6 del Convenio a la adopción de medidas cautelares provisionales ${ }^{27}$. El Tribunal constató que el art. 47 de la Carta de Derechos Fundamentales de la Unión Europea, que garantiza el derecho a un juicio justo, a diferencia del art. 6 del Convenio, no restringe ese derecho a lo relacionado con «los derechos y obligaciones de carácter civil» o "acusaciones en materia penal» y no remite tampoco a la resolución final relativa a tales litigios. Esto implica que las garantías de un juicio justo deben aplicarse también a decisiones que no son definitivas, y en Micallef tal es la línea que sigue el Tribunal. Pero es oportuno indicar que en el mismo apartado en que se menciona la Carta (párr. 32) el Tribunal hace mención también de la jurisprudencia del Tribunal de Justicia, citando el asunto Denilauler contra Couchet Frères de $1980^{28}$. Aún cuando se refiere a una decisión anterior incluso a la misma aprobación de la Carta, es ya una muestra de que el Tribunal toma en cuenta no solo el derecho de la Unión, sino también, y progresivamente, su interpretación por la jurisprudencia del Tribunal de Justicia.

Como era de esperar, la cita, no solo de la Carta sino también de la jurisprudencia del Tribunal de Justicia, se intensificó en las sentencias del Tribunal de Estrasburgo a partir de la entrada en vigor de la Carta con fuerza vinculante para las instituciones de la Unión. A partir de ese momento, entra en juego la jurisdicción del Tribunal de Luxemburgo para la aplicación e interpretación de la Carta y la garantía de los derechos fundamentales allí establecidos; y en consecuencia lógica, el Tribunal de Estrasburgo viene a tener en cuenta progresivamente no solo los mandatos de la Carta como elemento interpretativo del Convenio, sino también la jurisprudencia del Tribunal de Luxemburgo como elemento interpretativo de la Carta. La repercusión de esta sobre las decisiones del Tribunal de Estrasburgo se lleva a cabo pues tanto en forma inmediata como mediata, a través de las sentencias del Tribunal de Justicia.

También en este aspecto pueden apreciarse varios grados en la intensidad de la proyección del sistema de protección de derechos humanos de la Unión sobre el sistema del Convenio. En muchas resoluciones, esa proyección se traduce en la utilización, mediante citas en la sección «Derecho internacional y europeo relevante» de la jurisprudencia de Luxemburgo como apoyo o refuerzo, tácito o implícito, de los razonamientos del Tribunal Europeo; en otros, el apoyo se lleva a cabo explícitamente, utilizando la jurisprudencia de Luxemburgo para reforzar los argumentos incluidos en la fundamentación

27 Sentencia del TEDH de 15 de octubre de 2009, Micallef c. Malta, CE:ECHR: 2009:1015JUD001705606.

28 Sentencia del Tribunal de Justicia de 21 de mayo de 1980, Denilauler, 125/79, EU:C:1980:130. 
jurídica de la sentencia; en algún caso, la jurisprudencia del Tribunal de Justicia en la interpretación de la Carta ha servido para apoyar un alteración de la línea seguida hasta el momento por el Tribunal de Estrasburgo.

En lo que se refiere al grado inicial de proyección de la jurisprudencia de Luxemburgo, el Tribunal Europeo procede a citar esa jurisprudencia en la citada sección «Derecho internacional y europeo relevante» de sus sentencias, pero sin trasladar la cita de esa jurisprudencia a la fundamentación jurídica de su resolución; podría hablarse así de la utilización de la jurisprudencia de Luxemburgo como apoyo tácito o implícito de esa fundamentación. Un ejemplo al respecto podría ser la sentencia en el caso Roman Zakharov contra Rusia, del año 2015, particularmente relevante por cuanto Rusia no es parte de la Unión Europea, lo que no impide al Tribunal citar en esa sección sentencias de la Corte de Luxemburgo con proyección sobre el tema a tratar. En el caso, relativo a la intervención de las autoridades en el control y supervisión de comunicaciones, el Tribunal Europeo se refiere, en la sección de «Derecho internacional y europeo relevante» a que la sentencia del Tribunal de Justicia de 8 de abril de 2014 en los casos acumulados Digital Rights Ireland y Seitinger and Others había declarado inválida la Directiva 2006/24/EC sobre la obligación de retención por empresas de comunicación, durante períodos desde seis meses a dos años, de determinados datos para su eventual inspección estatal y que, en consecuencia, la obligación de retener esos datos representaba una interferencia con los derechos de respeto a la vida privada y la privacidad de las comunicaciones, garantizada por el art. 7 de la Carta, y la protección de datos personales garantizadas por el art. 8 de la misma ${ }^{29}$. Habida cuenta del sentido de la sentencia de Estrasburgo en Roman Zakharov, condenatoria de la intervención de las comunicaciones llevada a cabo por el derecho ruso por vulneración del art. 8 del Convenio, la cita de esa jurisprudencia de Luxemburgo representaba un apoyo implícito de la posición del Tribunal en la interpretación de ese art. $8^{30}$.

El Tribunal de Estrasburgo ha mantenido en muchos otros casos una utilización similar de la jurisprudencia del Tribunal de Justicia, como apoyo implícito de sus decisiones. Así, en Molla Sali contra Grecia, de $2018^{31}$, puede apreciarse una metodología similar, esta vez con referencia a un Estado integrado en la Unión Europea; en un caso relativo a la igualdad de derechos

29 Sentencia del Tribunal de Justicia de 8 de abril de 2014, Digital Rights Ireland, C-293/12, EU:C:2014:238.

30 Sentencia Roman Zakharov, citada en nota 15.

31 Sentencia del TEDH de 19 de diciembre de 2018, Molla Sali c. Grecia, CE: ECHR:2018:1219JUD002045214. 
en materia hereditaria, la sentencia cita como "Derecho relevante» no solo el art. 21 de la Carta, sino también su interpretación por el Tribunal de Justicia, en cuanto este, el año 2008, en el asunto Coleman y en 2015 en CHEZ Razpredelenie Bulgaria, se refirió a la cuestión de la discriminación por asociación basada en el origen étnico ${ }^{32}$. El Tribunal de Estrasburgo llega a una conclusión de vulneración de los arts. 14 del Convenio y 1.1 del Protocolo 1 en una línea que muestra (aún sin hacer referencia expresa a ella) la influencia de la jurisprudencia de Luxemburgo.

Pero la proyección de esa jurisprudencia en las decisiones del TEDH no se detiene en estos supuestos. Pues no faltan sentencias de Estrasburgo en que la jurisprudencia de Luxemburgo es citada expresamente como apoyo o refuerzo (aun cuando no se establezca como ratio decidendi de la fundamentación jurídica de la decisión del Tribunal). Un ejemplo (contemporáneo del citado caso Zakharov) pudiera ser la sentencia en el caso Delfi contra Estonia, del año 2015, relativa a la responsabilidad de empresas titulares de portales de Internet respecto de mensajes injuriosos reproducidos en esos portales. El Tribunal, al pronunciarse sobre la cuestión de si la responsabilidad de los autores de esos comentarios pudiera servir como alternativa razonable a la responsabilidad del portal de Internet, expresa que el Tribunal

se refiere en este aspecto a la reciente sentencia del Tribunal de Justicia de la Unión Europea en Google Spain SL y Google Inc, en que ese Tribunal, aun cuando en un contexto diferente, se ocupó del problema de la disponibilidad en Internet de información que afectara seriamente a la vida privada de una persona durante un largo período de tiempo, y encontró que los derechos fundamentales del individuo prevalecían sobre el interés económico del operador de una maquina de búsqueda, y sobre los intereses de otros usuarios de Internet $^{33}$.

La conclusión del Tribunal sobre la vulneración del art. 8 del Convenio se apoya pues en forma destacada en la jurisprudencia de Luxemburgo que cita.

Un ejemplo más reciente de esta influencia de la jurisprudencia del TJUE en aplicación de la Carta sobre la interpretación del Convenio por el TEDH pudiera ser la sentencia de este en el caso Breyer contra Alemania, de 2020. Lo que se planteaba en el caso era la conformidad con el art. 8 del Convenio de la aplicación de una disposición de la Ley de Telecomunicaciones alemana

32 Sentencias del Tribunal de Justicia de 17 de julio de 2008, Coleman, C-303/06, EU:C:2008:415 y e 16 de julio de 2015, CHEZ Razpredelenie Bulgaria, C-83/14, EU:C:2015:480.

33 Sentencia del TEDH de 16 de junio de 2015, Delf c. Estonia, CE:ECHR: 2015:0616JUD006456909, párr. 47. 
según la cual las empresas de telecomunicación deberían recoger y almacenar las referencias personales de todos sus clientes, incluyendo los usuarios de tarjetas SIM prepagadas. Los recurrentes eran usuarios de esas tarjetas, y por lo tanto debían suministrar a la empresa proveedora sus referencias personales, como sus números de teléfono, fecha de nacimiento, nombre y dirección. El Tribunal, consideró que no había habido vulneración del Convenio, al tratarse de una injerencia legítima y proporcionada. Para ello hizo referencia especial a la jurisprudencia del Tribunal de Justicia, en interpretación de los arts. 7 y 8 de la Carta y, particularmente, entre otras, tuvo en cuenta la sentencia del Tribunal de Justicia en la sentencia Ministerio Fiscal, de 2018:

Ciertamente, los datos de que se trata en este caso se asemejan notablemente a los tratados en una cuestión preliminar, Ministerio Fiscal. Como el Tribunal de Justicia de la Unión Europea señaló en ese caso, los datos en cuestión «no hacen posible determinar precisamente la fecha, hora, duración o receptores de las comunicaciones realizadas con la tarjeta o tarjetas SIM en cuestión, ni los lugares en que esas comunicaciones tuvieron lugar o la frecuencia de esas comunicaciones con personas específicas en un período determinado. Por lo tanto, eso datos no permiten obtener conclusiones precisas respecto de la vida privada de las personas a que esos datos se refieren». El Tribunal de Justicia en consecuencia concluyó que el acceso a los datos en cuestión no podría definirse como una injerencia grave en los derechos fundamentales de las personas cuyos datos se veían afectados ${ }^{34}$.

A la luz de la decisión finalmente adoptada por el Tribunal de Estrasburgo (que no apreció en el caso vulneración del art. 8) y de su fundamentación, no parece difícil deducir que la sentencia del Tribunal de Justicia representó en la práctica un elemento importante de su ratio decidendi.

\section{LA CARTA DE DERECHOS Y EL DIÁLOGO ENTRE ESTRASBURGO Y LUXEMBURGO: LOS CASOS SOBRE EL NE BIS IN IDEM}

Posiblemente, uno de los mejores ejemplos de la repercusión de la Carta de Derechos sobre el sistema del Convenio y la jurisprudencia del Tribunal de Estrasburgo pudiera ser el representado por el diálogo, con interacción recíproca, entre los tribunales de Estrasburgo y Luxemburgo, referente a la prohibición del ne bis in idem que se encuentra en el art. 4 del

34 Sentencia del TEDH de 30 de enero de 2020, Breyer c. Alemania, CE:ECHR: 2020:0130JUD005000112, párr. 94; donde se cita la Sentencia del Tribunal de Justicia de 2 de octubre de 2018, Ministerio Fiscal, C-207/16, EU:C:2018:788. 
Protocolo 7 al Convenio, y en el art. 50 de la Carta de Derechos Fundamentales de la Unión Europea ${ }^{35}$. Este diálogo presenta la peculiaridad, además, de haberse originado en las conclusiones del abogado general en el caso Akerberg Fransson ante el TJUE ${ }^{36}$.

La cuestión referente a la prohibición del ne bis in idem se había planteado ante el Tribunal de Estrasburgo, en varios casos, en cuanto a cuándo había que apreciar que efectivamente, y contrariamente a esa prohibición, se había producido un doble encausamiento penal por los mismos hechos. En los últimos años, el Tribunal, para la resolución de esos casos, partía de la fijación, en forma general, de su jurisprudencia llevada a cabo en el caso Zolotukhin contra Rusia, del año $2009^{37}$. Valga decir que el Tribunal optó en Zolotukhin claramente por el concepto fáctico o naturalista de «infracción», definido no por la calificación legal de los hechos en cada ordenamiento nacional, sino por la conducta o comportamiento fáctico del afectado. En el caso resuelto en Zolotukhin (que versaba sobre una doble sanción impuesta a un militar), el Tribunal decidió que el procedimiento entablado contra el recurrente en la vía penal se refería esencialmente a la misma conducta por la que ya había sido declarado culpable en vía administrativa, por lo que la dualidad de procedimientos sancionadores sobre los mismos hechos debía llevar a considerar en todo caso la existencia de una vulneración del principio ne bis in idem. En lo que se refiere a la naturaleza de esos procedimientos sancionadores, el Tribunal se remitía a su doctrina en el caso Engel contra Países Bajos, de 1976, para su calificación o no como penales ${ }^{38}$.

Ahora bien, la doctrina sentada en Zolotukhin en 2009 se vio modificada, con ocasión de un supuesto en que los recurrentes, dos contribuyentes noruegos, habían sido sancionados en vías administrativa y penal por una misma infracción tributaria. La nueva posición, que implicaba la admisión en algunos casos de una dualidad de procedimientos sancionadores por los mismos hechos, se fijó en la sentencia en el caso $A$ y $B$ contra Noruega, del año 2016.

La alteración de la doctrina del Tribunal encuentra alguno de sus orígenes en el procedimiento ante el Tribunal de Justicia en el caso Åkerberg Fransson,

35 Para un tratamiento más amplio, me remito a mi trabajo: López Guerra (2019: 9-26).

36 Conclusiones del abogado general Cruz Villalón, Åkerberg Fransson, C-617/10, EU:C: 2012:340.

37 Sentencia del TEDH de 10 de febrero de 2009, Zolotukhin c. Rusia, CE:ECHR: 2009:0210JUD001493903.

38 Sentencia del TEDH de 8 de junio de 1976, Engel y otros c. Países Bajos, CE:ECHR: 1976:0608JUD000510071. 
de 2013. En Akerberg Fransson, el Tribunal de Justicia aceptó en el caso la aplicación de la doctrina del Tribunal de Estrasburgo sobre la apreciación de si se había producido una dualidad de procedimientos sancionadores sobre los mismos hechos, dejando a la discreción del juez nacional la determinación de si se había producido una condena penal en concurrencia con una segunda sanción $^{39}$. En sus conclusiones, el abogado general (en el caso, Cruz Villalón) expresó sus reservas respecto de la aplicación mecánica de la cláusula del art. 4 del Protocolo 7 en el ámbito del derecho de la Unión. El abogado general pudo así señalar que:

A diferencia de otros derechos recogidos en el CEDH, el derecho previsto en el artículo 4 del Protocolo 7 del CEDH no ha sido unánimemente aceptado por los Estados firmantes del Convenio, entre los que se incluyen varios Estados miembros de la Unión. A la fecha de lectura de estas conclusiones, el Protocolo 7 aún no ha sido ratificado por Alemania, Bélgica, Países Bajos y Reino Unido. Entre los Estados que sí lo han ratificado, Francia ha formulado una reserva al artículo 4 del citado Protocolo, limitando su aplicación únicamente a las infracciones de naturaleza penal. Asimismo, con ocasión de la firma, Alemania, Austria, Italia y Portugal han formulado varias declaraciones apuntando a la misma circunstancia: el alcance limitado del artículo 4 del Protocolo 7, cuya protección únicamente alcanza a la doble sanción 'penal', en el sentido contemplado por el ordenamiento interno. [...] Lo anterior muestra con claridad y expresividad cómo los problemas suscitados por la doble sanción administrativa y penal adolecen de una considerable falta de consenso entre los Estados miembros de la Unión. El carácter problemático del cuadro se reafirma si atendemos a las negociaciones sobre la futura adhesión de la Unión al $\mathrm{CEDH}$, en las que los Estados y la Unión han decidido excluir, de momento, a los Protocolos del $\mathrm{CEDH}$, incluido el que aquí nos concierne ${ }^{40}$.

Lo relevante es que, para resolver el caso ante él, en su sentencia $A y$ $B$ contra Noruega, el Tribunal de Estrasburgo tiene en cuenta la posición crítica del abogado general, para revisar su jurisprudencia anterior. Tras haber reproducido parte de los argumentos del abogado general en la sección sobre «Derecho relevante», en sus razonamientos finales el Tribunal expone que:

El Tribunal ha tomado nota, además, de la observación realizada por el Abogado General ante el Tribunal de Justicia de la Unión Europea en el caso Fransson (ver $\$ 51$ más arriba) es decir, que la imposición de sanciones tanto de Derecho penal como

\footnotetext{
39 Sentencia del Tribunal de Justicia de 26 de febrero de 2013, Åkerberg Fransson, C-617/10, EU:C:2013:105.

40 Conclusiones Åkerberg Fransson citadas en nota 36, puntos 72 y 73.
} 
de Derecho administrativo respecto de la misma infracción es práctica extendida en los Estados miembros de la Unión Europea, especialmente en materias como impuestos, políticas de protección del medio ambiente y seguridad pública. El Abogado General también señaló que la forma en que esas sanciones se acumulaban variaba enormemente entre los distintos ordenamientos, y se refirió a particularidades específicas de cada uno de los distintos Estados miembros; en la mayoría de los casos tales particularidades se habían adoptado con el fin de moderar los efectos de la imposición de una doble sanción por las autoridades públicas ${ }^{41}$.

El Tribunal, para determinar si se había producido una dualidad de procedimientos sancionadores contraria al ne bis in idem, parte de la libertad de los Estados a la hora de organizar los procedimientos relativos a infracciones del ordenamiento. En los términos de la sentencia, «los Estados podrán, legítimamente, elegir respuestas legales complementarias a conductas socialmente ofensivas (como el no cumplimiento de regulaciones de tráfico o la evasión de impuestos) a través de procedimientos distintos que formen un todo coherente a efectos de enfrentarse con aspectos diferentes del problema social en cuestión, siempre que las respuestas jurídicas acumuladas no den lugar a una carga excesiva para el individuo afectado ${ }^{42}$.

El Tribunal, tras revisar su jurisprudencia anterior sobre esta cuestión, tiene en cuenta las observaciones arriba mencionadas del abogado general ante el Tribunal de Justicia en el caso Akerberg Fransson y señala que debe comprobar si efectivamente se ha producido una situación de doble encausamiento en detrimento de los afectados o si por el contrario (y pese a la existencia de dos procedimientos sancionadores que podrían calificarse, ambos, de penales) se trata de un sistema coherente e integrado que se enfrenta con diversos aspectos de una infracción de forma previsible y proporcionada, formando un todo interrelacionado, de forma que la persona afectada no se vea sometida a un tratamiento injusto ${ }^{43}$.

41 Sentencia del TEDH de 15 de noviembre de 2016, $A$ y $B$ c. Noruega, CE:ECHR: 2016:1115JUD002413011, párr. 118.

42 Ibid., párr. 121.

43 En el caso, el Tribunal considera que el efecto del art. 4 del Protocolo 7 no prohíbe que los Estados prevean la imposición de una sanción administrativa caso de impago de impuestos, incluso en aquellos casos más serios en que también cabe una persecución penal. En las circunstancias del caso, la posible imposición de una sanción en ambos procedimientos, administrativo y penal, era previsible para los afectados; además, ambos procedimientos se habían desarrollado en paralelo y estaban estrechamente conectados de forma que los hechos establecidos en uno de ellos habían sido aceptados en el segundo. Por otro lado, la condena acordada en el procedimiento penal había tenido 
No deja de resultar interesante, como muestra del diálogo entre los tribunales de Estrasburgo y Luxemburgo en la aplicación tanto del Convenio como de la Carta, que la línea jurisprudencial iniciada en el caso $A$ y $B$ contra Noruega por el Tribunal Europeo de Derechos Humanos haya encontrado seguimiento (si bien con un razonamiento paralelo) en la sentencia del Tribunal de Justicia de 20 de marzo de 2018 en el caso Luca Menci ${ }^{44}$ y ello pese a las conclusiones del abogado general contrarias a seguir la línea marcada por el Tribunal de Estrasburgo ${ }^{45}$.

En el caso, el Tribunal de Luxemburgo hubo de responder a la cuestión prejudicial planteada por el Tribunal de Bérgamo (tribunal de distrito) en el sentido de si se oponía el art. 50 de la Carta Europea de Libertades Fundamentales $^{46}$ (interpretado a la luz del art. 4 del Protocolo 7 al Convenio Europeo de Derechos Humanos y de la jurisprudencia del Tribunal Europeo de Derechos Humanos relativa a dicho artículo) a la posibilidad de tramitar un proceso penal que tuviera por objeto un hecho (impago del IVA) por el cual se hubiera impuesto a la persona imputada una sanción administrativa irrevocable.

El Tribunal de Justicia responde a la cuestión llevando a cabo una interpretación del art. 50 de la Carta que le lleva a considerar que efectivamente la injerencia en el caso en el derecho derivado del art. 50 de la Carta al ne bis in idem cumple con las exigencias derivadas del mismo: considera que la imposición de una segunda sanción constituye una injerencia expresamente prevista por la ley; responde a un interés protegido por la ley y relevante en materia económica, como es el representado por las percepciones por el IVA. Por ello, la eventual sanción resulta proporcionada a los intereses en juego. Se trata de una sanción previsible para el afectado, y para su imposición la ley prevé fórmulas para que no resulte desproporcionadamente severa.

en cuenta la sanción fiscal impuesta administrativamente. Por ello, la sentencia del TEDH llega a la conclusión de que la conexión entre ambos procedimientos excluía la dualidad prohibida por el art. 4 del Protocolo 7. El Tribunal a estos efectos estima irrelevante el orden cronológico de procedimientos, esto es, si la primera sanción en adquirir firmeza fue administrativa o penal. Así y todo, recomienda, como en algún caso anterior, como vía más adecuada la de que el examen y decisión sobre los diversos aspectos de la infracción se lleven a cabo en el mismo procedimiento.

44 Sentencia del Tribunal de Justicia de 20 de marzo de 2018, Menci, C-524/15, EU:C: 2018:197.

45 Conclusiones del abogado general Campos Sánchez-Bordona, Menci, C-524/15, EU:C:2017:667.

$46 \mathrm{El}$ art. 50 de la Carta dispone que «nadie podrá ser juzgado o condenado penalmente por una infracción respecto de la cual ya haya sido absuelto o condenado en la Unión mediante sentencia penal firme conforme a la ley». 
Para reforzar sus argumentos, el Tribunal de Justicia acude a la jurisprudencia de Estrasburgo en $A$ y $B$ contra Noruega (bajo el signo de la «coherencia necesaria») para apuntalar su nueva interpretación del art. 50 de la Carta.

A este respecto, el Tribunal Europeo de Derechos Humanos ha declarado que la acumulación de procedimientos y sanciones tributarios y penales que repriman la misma infracción de la ley tributaria no viola el principio ne bis in idem consagrado en el artículo 4 del Protocolo n.7 al Convenio Europeo de Derechos Humanos cuando los procedimientos tributarios y penales de que se trate presenten un vínculo material y temporal suficientemente estrecho [...].

De este modo, las exigencias a las que el artículo 50 de la Carta, en relación con el artículo 52, apartado 1 de esta, somete una eventual acumulación de procesos y sanciones penales y procedimientos y sanciones administrativos de carácter penal [...] garantizan un nivel de protección del principio ne bis in idem que no menoscaba el garantizado por el artículo 4 del Protocolo 7 al CEDH, tal como lo interpreta el Tribunal Europeo de Derechos Humanos ${ }^{47}$.

El Tribunal de Justicia viene a adoptar, si bien no con idénticos razonamientos, la línea establecida por el Tribunal de Estrasburgo en $A$ y $B$ contra Noruega, sentencia que cita expresamente. Este parece ser, por el momento, el último capítulo de la saga ne bis in idem en el ámbito europeo.

\section{A MODO DE CONCLUSIÓN}

La proyección de la Carta de Derechos Fundamentales de la Unión Europea sobre el sistema del Convenio y sobre la jurisprudencia del Tribunal de Estrasburgo se refleja, como se ha dicho, en un conjunto de sentencias de este, que versan sobre muy distintas materias. Pero la apreciación del alcance y significado de esa proyección no resulta solo del examen de esas sentencias en concreto, sino también, y más generalmente, de la constatación de que el Tribunal de Estrasburgo es consciente de que tanto el Convenio como la Carta son expresión de una realidad común, que exige la acción también común de los mecanismos de ambos sistemas en garantía de los derechos fundamentales. Nada podría expresar mejor esa apreciación que las palabras del voto particular concurrente de los jueces Spano y Pavli en Romeo Castaño contra Bélgica, de 2019:

47 Sentencia Menci, citada en nota 44, apdos. 61 y 62. 
El Convenio Europeo de Derechos Humanos no subsiste aislado de su contexto de aplicación regional. Veintiocho de los cuarenta y siete Estados miembros del Consejo de Europa están igualmente adheridos a la Unión Europea («la UE»). Interesa, por tanto, compaginar las garantías mínimas de los derechos humanos enunciados en el Convenio con las exigencias de uniformidad y armonización de las normas en el marco del Derecho de la UE, que también deben ser conformes con la Carta de los Derechos Fundamentales de la Unión, cuya esencia debe tener en cuenta la evolución que se produzca en el seno del Tribunal Europeo de Derechos Humanos cuando los derechos contenidos en la Carta se correspondan con los garantizados del Convenio (véase el artículo $52 \$ 3$ de la Carta). Este "propósito de simetría» se manifiesta particularmente en los mecanismos de reconocimiento mutuo de la UE basados en el principio de confianza mutua, tal como lo examinó últimamente el Tribunal Europeo de Derechos Humanos en su sentencia de Gran Sala Avotinš contra Letonia, de 2016 y que posteriormente se aplicó en el contexto de la Orden Europea de Detención y Entrega («la OEDE») en el asunto Pirozzi contra Bélgica, de $2018^{48}$.

\section{Bibliografía}

Dickson, B. (2015). The EU Charter of Fundamental Rights in the case law of the European Court of Human Rights. European Human Rights Law Review, 1, 27-40.

Engel, D. (2015). Der Beitritt der Europäische Union zur EMRK. Tübingen: Mohr Siebeck. Disponible en: https://doi.org/10.1628/978-3-16-154241-1.

López Guerra, L. (2019). Ne bis in idem en la jurisprudencia del Tribunal Europeo de Derechos Humanos. Revista Española de Derecho Europeo, 69, 9-26.

Rauchegger, C., Lambrecht, S. (2016). European Union: the EU's Attitude to the ECHR. En P. Popelier y otros (dirs.). Criticism of the European Court of Human Rights. Shifting the Convention System: Counterdynamics at the National and EU Level (pp. 41-72) Cambridge: Intersentia. Disponible en: https://doi. org/10.1017/9781780685175.003.

Rubio Llorente, F. (2002). Una Carta de dudosa utilidad. En F. J. Matía Portilla (dir.). La protección de los derechos fundamentales en la Unión Europea (pp. 169-201). Madrid: Civitas.

48 Véase el voto particular a la Sentencia del TEDH de 9 de julio de 2019, Romeo Castaño c. Bélgica, CE:ECHR:2019:0709JUD000835117. 